\title{
Phonological treatment approaches for spoken word production in aphasia
}

\author{
Elizabeth Brookshire Madden, Ph.D., CCC-SLP \\ School of Communication Science and Disorders \\ Florida State University \\ Reva M. Robinson, M.S., CCC-SLP \\ Department of Speech \& Hearing Sciences \\ University of Washington \\ Diane L. Kendall, Ph.D., CCC-SLP \\ VA Puget Sound Healthcare System \\ Department of Speech \& Hearing Sciences \\ University of Washington \\ Department of Speech Language Pathology and Audiology \\ University of Pretoria
}

Correspondence:

Elizabeth Brookshire Madden, Ph.D., CCC-SLP

201 West Bloxham Street

Tallahassee, FL 32306-1200

Email: ebmadden@fsu.edu

Phone: 850-644-4088

Fax: 850-644-6639 


\begin{abstract}
This paper provides an overview of phonological treatment approaches for anomia in individuals with aphasia. The role of phonology in language processing, as well as the impact of phonological impairment on communication is initially discussed. Then, traditional phonologically-based treatment approaches, including phonological, orthographic, indirect, guided, and mixed cueing methods are described. Collectively, these cueing treatment approaches aim to facilitate word retrieval by stimulating residual phonological abilities. An alternative treatment approach, phonomotor treatment, is also examined. Phonomotor treatment aims to rebuild sub-lexical, phonological sequence knowledge and phonological awareness as a means to strengthen lexical processing and whole-word naming. This treatment is supported by a parallel-distributed processing model of phonology and therefore promotes multi-modal training of individual phonemes and phoneme sequences in an effort to enhance the neural connectivity supporting underlying phonological processing mechanisms. The paper concludes with suggestions for clinical application and implementation.
\end{abstract}

\title{
KEY WORDS
}

Aphasia, anomia, phonology, treatment, phonomotor 


\section{DISCLOSURES}

Elizabeth Brookshire Madden receives a salary from Florida State University.

Reva M. Robinson receives a salary from the University of Washington and VA Puget Sound Healthcare System.

Diane L. Kendall receives a salary from the University of Washington and the VA Puget Sound Healthcare System. She earns royalties from MedBridge, the continuing education provider referenced in this paper. 


\section{Contribution of phonology to language processing}

This issue of Seminars in Speech and Language is devoted to understanding how treatment approaches that target various cognitive processes, such as language, attention, memory, and executive function, influence the rehabilitation of aphasia. The specific cognitive processing domain discussed in this paper is phonology. Phonology encompasses the systematic ordering of sounds (i.e., phonemes). In English, there are 44 phonemes that can be sequenced in numerous combinations to yield all of the words in the English language. Knowledge and use of these phonemes and phonotactically-legal phoneme sequences may be seen as the foundation of language processing. This can be observed during language acquisition when children first discover the phonological sequence regularities of their language and then learn to assemble those sound sequences and associate them with semantic concepts in order to comprehend and produce language. ${ }^{1,2}$

This pivotal connection, or interaction, between phonology and semantics that supports language processing is commonly described by an interactive 2-step model of lexical retrieval. ., $4^{4}$ According to this model, word retrieval is made possible via bidirectional spreading activation that exists between phonological and semantic units in a lexical network. During a language comprehension task (e.g., following verbal directions), initially phonological representations are activated and subsequently activation of semantic knowledge follows. Conversely, during a language production task (e.g., naming an object), semantic representations are activated first and this engagement spreads to the phonological level. Regardless of which cognitive domain is initially engaged, the activation spreads bi-directionally. Thus, phonologic activation helps to trigger semantic representations and vice versa. We make quick reference to this language model to highlight that phonology is a fundamental and critical aspect of language processing that is 
required for lexical retrieval to be fully accessed and recognized. Without adequate phonological abilities, language processing breaks down and becomes errorful and inefficient.

For example, brain injury, most commonly stroke, can result in impaired phonological abilities and significantly disrupt language performance. Specifically, damage to left perisylvian cortical areas typically weakens representation and processing of phonemes and phoneme sequences. ${ }^{5,6}$ This type of injury often results in aphasia. Individuals with aphasia and phonological impairment are known to have difficulty with sound sequencing and produce phonemic paraphasias (e.g., saying “speen” for "spoon”). Moreover, impaired phonology in individuals with aphasia has been associated with wide spread cognitive processing difficulties including reading, ${ }^{7,8}$ writing, ${ }^{5}$ language comprehension,,${ }^{9,} 10$ language production, ${ }^{11,12}$ short-term memory ${ }^{13}$ and working memory ${ }^{14,15}$ dysfunction.

Given the importance of phonology in language processing, various phonologically-based treatment approaches have been designed and implemented to address language impairment in aphasia. Some of these phonological treatments have targeted reading and writing disorders, ${ }^{5,7}$, 16, 17 as well as auditory comprehension impairment. ${ }^{18}$ However, most phonological treatments in the aphasia literature have targeted word retrieval impairment (i.e., anomia), which is the focus of this paper. First, an overview of traditional phonologically-based treatment approaches used to rehabilitate spoken word production abilities in persons with aphasia (PWA) will be described. Then, an alternative phonological treatment approach, phonomotor treatment, will be explained. Finally, recommendations for clinical practice will be suggested.

\section{Traditional Phonological Treatment Approaches}

Traditionally, phonologically-based anomia treatments in aphasia have used different cueing methods that aim to elicit the name of a picture stimulus. It is not the intention of this 
paper to provide a thorough description of all of these treatment approaches (for a detailed review of phonological treatment approaches, the reader is referred to Nickels ${ }^{19}$ and Wisenburn and Mahone ${ }^{20}$ ). Instead, we will briefly describe five commonly implemented phonologicallybased cueing treatment approaches: phonological cueing, orthographic cueing, indirect cueing, guided self-cueing, and mixed cueing.

Treatments employing phonological cueing typically present a picture stimulus of the target word and then provide a hierarchy of cues including rhyming cues, first phoneme cues, first syllable cues, and/or verbal models that prompt the individual with aphasia to name the target word. ${ }^{21,22}$ Given the close relationship between graphemes and their corresponding phonemes, orthographic cues are often used in phonologically-based treatments. In addition to the phonological cues listed above, treatment approaches using orthographic cueing usually involve showing the first letter or grapheme of the target word, matching letters to sounds, and/or providing a written model along with the picture stimulus that encourages the PWA to read aloud the target word. ${ }^{23,24}$

Contextual priming, a form of indirect cueing, is another phonological cueing treatment method that has been utilized with individuals with aphasia. ${ }^{25,26}$ Contextual priming entails repeated naming of phonologically related words. Typically, a PWA will attempt to name a set of three pictures whose names may or may not be phonologically similar at the beginning (e.g., pitcher, pillow, picture) or end of the word (e.g., chain, cane, brain). No overt cues are provided by the clinician, and therefore this treatment approach is considered indirect since the presence or absence of phonological similarity among the treatment items is not explicitly highlighted. Hendricks and colleagues ${ }^{27}$ concluded that phonological neighborhood affected naming ability in their contextual priming paradigm. Specifically, front-matched pictures representing words 
with high density phonological neighborhoods (i.e., phonologically similar words) were named the most accurately.

Phonological component analysis $\left(\mathrm{PCA}^{28,29}\right)$ treatment is a well-known aphasia treatment program that employs guided self-cueing to facilitate word retrieval. In PCA, the patient attempts to independently name a picture and then generate five phonological components of the target word (i.e., rhyme, first sound, first sound association, final sound, and number of syllables). If unable to spontaneously generate a phonological component, the PWA is guided by the clinician. Specifically, for each phonological component the PWA is provided with up to three choices that are visually presented and read aloud by the clinician.

The element of choice provided in PCA is proposed to elicit a "more active engagement”30(p 398) of the linguistic system and induce deeper cognitive processing compared to treatments that directly provide a phonological cue (e.g., repetition cue) without the need for patient reflection or choice. ${ }^{30}$ Leonard and colleageus ${ }^{30}$ found the majority of research participants (7 out of 10) demonstrated significant gains after PCA treatment, supporting the effectiveness of patient choice and subsequent decision-making involved in PCA. In addition, some credit the success of PCA treatment to the patient learning a naming strategy that can be used when attempting to name untrained items outside of therapy. ${ }^{29}$

Finally, treatment protocols that involve a mixture of phonological and semantic cues are also a popular choice for the rehabilitation of spoken word production impairment in aphasia. It is important to note that all of the phonologically-based treatments mentioned thus far could be said to use a mixed cueing approach since the target words in those treatment approaches are represented by picture stimuli that automatically engage semantic processing. However, treatment approaches that are usually considered to employ mixed cueing methods explicitly 
incorporate semantic cues along with phonological cues, in addition to using picture stimuli, to facilitate word retrieval. This type of treatment approach may include utilizing a cueing hierarchy that first activates semantic aspects of the target word (e.g., cues to state the function/use of the target word) and then progresses to explicitly activate phonological aspects of the target word (e.g., providing the first and/or second phonemes). ${ }^{31}$ For example, Thompson and colleagues $^{32}$ applied a cueing treatment that started with a sentence completion cue (e.g., "You fly in $a \_$_ ”), followed by sentence completion with first phoneme cue (e.g., "You fly in a $p_{\ldots}$ ”), and ended with sentence completion with the verbal model (e.g., "You fly in a plane.”). Another semantic-phonologic treatment approach ${ }^{33}$ involves requesting the PWA to repeat the picture name three times and then respond to a series of yes/no questions focused on semantic (e.g., "Is a blouse similar to a vest?”) and phonological (e.g., “Does blouse start with /b/?”) attributes of the target word. A final example of a mixed cueing treatment is the computer-administered program, Multicue. ${ }^{34}$ Multicue allows the PWA to choose between semantic cues (e.g., select icons for “Word Meaning” or “When do you use it?”) or phonological/orthographic cues (e.g., select icon "Word Form") to discover which type of cue, or combination of cues, is most beneficial to naming the picture displayed on the computer monitor.

The five aforementioned phonologically-based treatment approaches, as a whole, have demonstrated significant acquisition and maintenance treatment effects; however, typically only trained items improve and generalization to untrained items remains limited. ${ }^{28,30,35}$ Some authors $^{28,21,36}$ have explicitly stated that generalization to untrained items should not be expected in a purely phonological therapy because training is unique for each target word (i.e., picture by picture training with phonological cueing specific to each stimulus), and therefore improvement on unexposed lexical items is not anticipated. This may help account for Wisenburn and 
Mahoney’s ${ }^{20}$ systematic review finding that most phonological treatments resulted in generalization less often than semantically-based treatments.

As we will discuss below, active rehabilitation of phoneme sequence knowledge and phonological processing mechanisms may be key to promoting generalization in phonological treatments for anomia. It can be argued that the traditional phonological treatment approaches described above are not intended to be treatments for phonology that aim to repair phonological processing and the underlying phonological system itself. Instead, those treatments are designed to capitalize on residual phonological processing to facilitate word naming. That said, it is important to note there are many clinical situations when word-specific phonological treatment approaches should be used. For example, when the number of therapy sessions is limited and the goal is to produce a small number of personally-relevant and functional words, it is appropriate and effective to use traditional phonological treatment approaches, which should allow for acquisition and maintenance of a specific set of lexical items. However, based on the discussion above, it is unlikely that generalization beyond those trained items will occur.

An alternative to phonemic cueing therapies is to train the systematic regularities of phonology with the overarching goal of improving production of words trained in therapy (acquisition effect), maintaining those changes over time (maintenance effect), and achieving generalization to untrained words in daily conversation (generalization effect). Targeting language regularities is arguably more desirable than training one word at a time since it would be very difficult and time intensive to train every word in the dictionary one word or one semantic domain at a time. Since the translation of all word knowledge (i.e., lexical-semantic representations) to spoken production requires activation of the same finite set of phonological representations, training the full repertoire of individual phonemes and selected phoneme 
sequences should, in theory, result in improved word retrieval and broader generalization. Phonomotor treatment ${ }^{12,6,37}$ is one such word retrieval treatment that specifically targets phonological processing and phonological regularities (or phoneme sequence knowledge).

\section{Phonomotor Treatment}

Phonomotor treatment is a multi-modal treatment for phonology that was inspired by the Lindamood Phoneme Sequencing Program for Reading, Spelling, and Speech (LiPS $\left.{ }^{38}\right)$ and adapted for individuals with aphasia. The theoretical motivation behind phonomotor treatment, a connectionist, parallel-distributed processing (PDP) model of phonology, ${ }^{39}$ has been discussed in-depth elsewhere ${ }^{6,12}$ and will only be briefly reiterated here. This PDP model proposes that phonological representations (e.g., phoneme $/ p /$ ), are represented by distributed neural connections between auditory (e.g., auditory percept /p/), articulatory-motor (e.g., verbal production /p/), orthographic (e.g., letter “p”), and semantic/conceptual (e.g., knowledge that phoneme /p/ exists) domains that can be modified via experience and learning. Given the connectivity within and between domains, input into any domain of this phonological network will produce simultaneous activation in other domains. For example, input to the acoustic domain (e.g., hear $/ p /$ ) will automatically engage the motor domain (e.g., say “p”). Based on these theoretical assumptions, the basic idea supporting phonomotor treatment is that multimodal (e.g., auditory, motor, orthographic, tactile-kinesthetic) training of phonemes and phoneme sequences allows for the neural connectivity supporting phoneme sequence knowledge to be strengthened and enhanced. Furthermore, it is thought that if a PWA can achieve an adequate repertoire of phonological sequence knowledge during phonomotor treatment, he or she will be able to demonstrate continued improvement after therapy by applying this knowledge to real-world conversations and interactions. 
Phonomotor treatment description. Phonomotor is an intensive treatment that is typically delivered 2 hours/day, 5 days/week for 6 weeks for a total of 60 hours of treatment. This treatment aims to improve phonological processing and awareness through multi-modal practice with recognizing, producing, and manipulating phonemes in non-word (NW) and real word (RW) stimuli of increasing length and complexity. The treatment program is comprised of two stages with the first stage (approximately 20 hours) focused on training phonemes in isolation, and the second stage (approximately 40 hours) focused on training phoneme sequences.

In Stage 1, each English consonant and vowel is multi-modally trained via emphasizing motor description (e.g., "Tongue taps behind top teeth for /t/”), perceptual discrimination (e.g., “Are /t/ and /d/ same or different?”), articulatory-motor production (e.g., "Repeat /t/"), visual discrimination (e.g., "Look in the mirror, does your mouth match mine?" or "Show me the mouth picture for /t/.”), and graphemic representation (e.g., “What letter goes with /t/?”; see Figure 1). During this training, phonemes are categorized according to place or manner of articulation (e.g., lip, tongue, nose, or air sounds) and introduced in voiceless and voiced pairs (e.g., /t/ and /d/; /p/ and $/ b /)$.

Insert Figure 1 about here

Once the PWA is able to perceive and produce individual phonemes, Stage 2 begins and includes training phoneme sequences via phonological awareness tasks (e.g., "If this says 'peef', show me "pif"). Various materials, including mouth pictures, wooden blocks, and letter tiles, are used to represent and train the phonemes and phoneme sequences. Training progresses from simple one-syllable phoneme sequences (e.g., "eep”) to more complex one- and two-syllable 
NW (e.g., “broiz”; “chootee”) and RW (e.g., “plane”; “movie”) phoneme sequences. Nonword stimuli are introduced before real word stimuli to allow for exclusive training of the phonologic system, as lexical-semantics are inherently absent in non-word tasks. The nonword and real word stimuli (see Figure 2) were constructed to incorporate certain psycholinguistic principles (i.e., low phonotoactic probability and high neighborhood density) that have been shown to enhance word learning. ${ }^{40}$ Throughout treatment, feedback is provided via Socratic questioning (e.g. "You said /b/. I said /p/. Are we the same or different?”; “Is your voice on or off?) to promote metacognitive awareness of task performance.

\section{Insert Figure 2 about here}

In summary, the key elements of phonomotor treatment delivery are to: a) always start with multi-modal training of phonemes in isolation; b) use nonword stimuli first; c) then introduce real word stimuli; d) employ phonological awareness tasks with all stimuli; e) use Socratic questioning; f) deliver treatment intensively (if possible); and, importantly, g) do not include picture stimuli, so as to limit engagement of lexical-semantic processes.

A phonomotor treatment protocol is provided as an appendix and is designed to assist with delivery of treatment. Additionally, an on-line video continuing education module created by the third author of this paper is available through Medbridge ${ }^{41}$ and contains additional details regarding implementation of this treatment protocol.

Summary of phonomotor treatment results. Kendall and Nadeau ${ }^{37}$ recently provided a detailed review of the current evidence supporting the efficacy of phonomotor treatment. To briefly summarize, there have been five Phase I trials and three Phase 2 trials of phonomotor 
treatment to date. Phonomotor treatment has produced significant acquisition (i.e., 1-week posttreatment) and maintenance (i.e., 3-months post-treatment) effects for naming of trained stimuli, as well as significant generalization to naming of untrained real words. ${ }^{12,}{ }^{6}$ Moreover, generalization has been seen across language tasks with improvement in untrained nonword repetition, ${ }^{6}$ as well as improvement in untrained real word and nonword reading ${ }^{42}$ and discourse $^{12}$ occurring for some participants after phonomotor treatment. Finally, changes in general cognitive processes, as reflected by changes in the types of naming errors produced over the course of treatment, have also been captured after phonomotor treatment. ${ }^{43,44}$

Phonomotor treatment limitations and considerations. Despite promising results, there are limitations to phonomotor treatment that need to be acknowledged. In particular, phonomotor treatment is limited regarding clinical feasibility due to the high intensity and frequency of treatment delivery. The treatment program has only been tested at an intense dosage and therefore cannot be easily implemented in the same manner in most clinical settings due to the insurance-restricted number of treatment sessions many clinicians face. Plans are currently underway, however, to conduct a research trial investigating the effects of massed (current dosage) versus distributed treatment dosage (1 hour/day, 3 days/week for 60 hours), which should help shed light on the necessary dosage of phonomotor treatment.

Additionally, phonomotor treatment is not successful with all PWA. The studies to date include a heterogeneous population of individuals with chronic aphasia with a wide range of cognitive-linguistic deficits. Therefore, it is unclear at this point who is most likely to benefit from phonomotor treatment. Nevertheless, after observing over fifty PWA complete phonomotor treatment across different trials, it seems imperative that individuals undergoing treatment not suffer from severe auditory comprehension impairment and demonstrate some remaining 
phonological skills. Understanding patient response to phonomotor treatment is another study currently underway. We anticipate the outcomes of this study will help us identify predictors of phonomotor treatment success.

\section{Clinical Applications and Conclusions}

This paper described several phonological treatment approaches for spoken word production impairment in aphasia. Most of the treatments reviewed focus on stimulating residual phonological abilities to improve access to whole-word naming, while phonomotor treatment takes an alternative approach and aims to rebuild sub-lexical, phonological sequence knowledge and phonological awareness as a means to strengthen lexical processing and whole-word naming. All of the treatment approaches mentioned have clinical value and it is not possible, or advisable, to directly compare these treatment approaches given that the treatments differ in selection of stimuli, tasks, outcome measures, treatment delivery, and patients. Instead, we highlight some key points below that we hope will benefit the reader's clinical practice:

1) Phonological impairment in aphasia is linked with wide-spread cognitive-linguistic deficits, and therefore assessment and treatment of phonology should be considered for all individuals with aphasia.

2) Traditional phonological cueing treatments typically target specific lexical items, which often limits generalization. In an effort to maximize treatment outcomes and enhance generalization effects, we suggest first targeting underlying phonological processes by training phonemes and phoneme sequences in as many modalities (i.e., auditory, articulatory-motor, orthographic, tactile-kinesthetic) as possible. This is in agreement with Nickels, ${ }^{19}$ who reports that phonological treatments that incorporate multi-modal and multi-component tasks appear to hold the most promise. It is likely worthwhile to 
attempt a traditional phonological therapy approach in conjunction with, or shortly after, a phonomotor-like therapy approach. Phonological cues will likely be more effective once the phonological system has been explicitly trained.

3) Phonological impairments do not exist in a cognitive vacuum. Therefore, additional treatment approaches should be pursued alongside treatments mentioned in this paper to address other linguistic impairments and maximize treatment outcomes. For example, the plan of care could involve a modified phonomotor program in conjunction with a treatment similar to Verb Network Strengthening Treatment $\left(\mathrm{VNeST}^{45}\right)$ to simultaneously target phonological and semantic aspects of word production. This treatment could be further tailored to include patient and caregiver training for continued home practice and maintenance after therapy. In addition to these impairment-based focused treatments, the functional communication needs of the patient should also be considered, perhaps via goals that take into account a life participation approach ${ }^{46}$ Since aphasia and word retrieval impairment are likely to be a life-long problem, it is also important to introduce psychosocial support strategies to help the PWA and his/her caregivers cope with the effects of aphasia that reach far beyond communication (e.g., stress). ${ }^{47}$

4) Each individual with aphasia is unique - premorbid skills, family support, lesion location and size, and language profile, are only a few of the factors that influence treatment outcomes. Therefore, the treatment approach adopted should be customized to suit her/his individual needs and circumstances. Considering patient goals, candidacy, and resources can significantly influence the selection and success of any treatment program. 
There is still much research to be conducted and much to be learned about best practices to address phonological impairment in aphasia; however, at this time, a good approach appears to involve carefully chosen stimuli and tasks that aim to deeply stimulate and rehabilitate the underlying phonological system, reinforce learning via multi-modal practice, and encourage patient-choice and self-assessment.

\section{ACKNOWLEDGEMENT}

The authors would like to acknowledge the United States Department of Veterans Affairs for providing tremendous funding for aphasia research, especially for the two grants (\#RRD3-1512W and \#1101RX001145-01A1) that supported this work.

\section{REFERENCES}

1. Gathercole SE. Is nonword repetition a test of phonological memory or long-term knowledge? It all depends on the nonwords. Memory and Cognition. 1995; 23(1):83-94.

2. Gathercole SE, Martin AJ. Interactive processes in phonological memory. In: Gathercole SE, ed. Models of Short Term Memory. East Sussex: Psychology Press, 1996:73-100.

3. Dell GS. A spreading-activation theory of retrieval in sentence production. Psychological Review. 1986; 963(3):283-321.

4. Dell GS, Schwartz MF, Martin N, Saffran EM, Gagnon DA. Lexical access in aphasic and nonaphasic speakers. Psychological Review. 1997; 104(4):801.

5. Beeson PM, Rising K, Kim ES, Rapcsak SZ. A treatment sequence for phonological alexia/agraphia. Journal of Speech, Language, and Hearing Research. 2010; 53(2):45068. 
6. Kendall DL, Oelke M, Brookshire CE, Nadeau SE. The influence of phonomotor treatment on word retrieval abilities in 26 individuals with chronic aphasia: an open trial. Journal of Speech, Language, and Hearing Research. 2015; 58:798-812.

7. Conway T, Heilman P, Rothi LJG, et al. Treatment of a case of phonological alexia with agraphia using the Auditory Discrimination in Depth (ADD) program. Journal of the International Neuropsychological Society. 1998; 4(6):608-20.

8. Kendall DL, Conway T, Rosenbek J, Gonzalez-Rothi L. Phonological rehabilitation of acquired phonologic alexia. Aphasiology. 2003; 17(11):1073-95.

9. Blumstein SE. The mapping from acoustic structure to the phonetic categories of speech: The invariance problem. Behavioral and Brain Sciences. 1998; 12(2):260-.

10. Milberg W, Blumstein SE, Dworetzky B. Phonological processing and lexical access in aphasia. Brain and Language. 1988; 34(2):279-93.

11. Nadeau SE. Phonology: A review and proposals from a connectionist perspective. Brain and Language. 2001; 79(3):511-79.

12. Kendall DL, Rosenbek JC, Heilman KM, et al. Phoneme-based rehabilitation of anomia in aphasia. Brain and Language. 2008; 105:1-17.

13. Allen CM, Martin RC, Martin N. Relations between short-term memory deficits, semantic processing, and executive function. Aphasiology. 2012; 26(3/4):428-61.

14. Baddeley AD, Hitch G. Working memory. Psychology of Learning and Motivation. 1974;8:47-89.

15. Friedman RB, Sample DM, Lott SN. The role of level of representation in the use of paired associate learning for rehabilitation of alexia. Neuropsychologia. 2002; 40(2):2234. 
16. Kiran S. Training phoneme to grapheme conversion for patients with written and oral production deficits: A model-based approach. Aphasiology. 2005; 19(1):53-76.

17. Yampolsky S, Waters G. Treatment of single word oral reading in an individual with deep dyslexia. Aphasiology. 2002; 16(4-6):455-71.

18. Morris J, Franklin S, Ellis AW, Turner JE, Bailey PJ. Remediating a speech perception deficit in an aphasic patient. Aphasiology. 1996; 10(2):137-58.

19. Nickels L. Therapy for naming disorders: Revisiting, revising, and reviewing. Aphasiology. 2002; 16(10-11):935-79.

20. Wisenburn B, Mahoney K. A meta-analysis of word-finding treatments for aphasia. Aphasiology. 2009; 23(11):1338-52.

21. Davis A, Pring T. Therapy for word-finding deficits: More on the effects of semantic and phonological approaches to treatment with dysphasic patients. Neuropsychological Rehabilitation. 1991; 1(2):135-45.

22. Wambaugh J. A comparison of the relative effects of phonologic and semantic cueing treatments. Aphasiology. 2003; 17(5):433-41.

23. Best W, Nickels L. From theory to therapy in aphasia: Where are we now and where to next? Neuropsychological Rehabilitation. 2000; 10(3):231-47.

24. Miceli G, Amitrano A, Capasso R, Caramazza A. The treatment of anomia resulting from output lexical damage: Analysis of two cases. Brain and Language. 1996; 52(1):150-74.

25. Fisher CA, Wilshire CE, Ponsford JL. Word discrimination therapy: A new technique for the treatment of a phonologically based word-finding impairment. Aphasiology. 2009; 23(6):676-93. 
26. Renvall K, Laine M, Martin N. Treatment of anomia with contextual priming: exploration of a modified procedure with additional semantic and phonological tasks. Aphasiology. 2007; 21(5):499-527.

27. Hendricks CT, Nicholas ML, Zipse L. Effects of phonological neighborhood density on the treatment of naming in aphasia. Aphasiology. 2014; 28(3):338-58.

28. Bose A. Phonological therapy in jargon aphasia: Effects on naming and neologisms. International Journal of Language and Communication Disorders. 2013; 48(5):582-95.

29. van Hees S, Angwin A, McMahon K, Copland D. A comparison of semantic feature analysis and phonological components analysis for the treatment of naming impairments in aphasia. Neuropsychological Rehabilitation. 2013; 23(1):102-32.

30. Leonard C, Rochon E, Laird L. Treating naming impairments in aphasia: Findings from a phonological components analysis treatment. Aphasiology. 2008; 22(9):923-47.

31. Linebaugh CW, Shisler RJ, Lehner L. Cueing hierarchies and word retrieval: A therapy program. Aphasiology. 2005; 19(1):77-92.

32. Thompson CK, Kearns KP, Edmonds LA. An experimental analysis of acquisition, generalisation, and maintenance of naming behaviour in a patient with anomia. Aphasiology. 2006; 20(12):1226-44.

33. Raymer AM, Ciampitti M, Holliway B, et al. Semantic-phonologic treatment for noun and verb retrieval impairments in aphasia. Neuropsychological Rehabilitation. 2007; 17(2):244-70.

34. Doesborgh S, Sandt-Koenderman MVD, Dippel D, Harskamp FV, Koudstaal P, VischBrink E. Cues on request: The efficacy of Multicue, a computer program for word finding therapy. Aphasiology. 2004; 18(3):213-22. 
35. Thompson CK, Raymer AM, Grand HL. Effects of phonologically based treatment on aphasic naming deficits: A model-driven approach. Clinical Aphasiology Conference. 1990; 20:239-61.

36. Macoir J, Routhier S, Simard A, Picard J. Maintenance and generalization effects of semantic and phonological treatments of anomia: A case study. Communication Disorders Quarterly. 2012; 33(2):119-28.

37. Kendall DL, Nadeau SE. The phonomotor approach to treating phonological-based language deficits in people with aphasia. Topics in Language Disorders. 2015; 36(2):109-22.

38. Lindamood P, Lindamood P. The Lindamood phoneme sequencing program for reading, spelling, and speech. 3rd ed. Austin, TX: Pro-Ed Publishing; 1998.

39. Nadeau SE. Phonology: A review and proposals from a connectionist perspective. Brain and Language. 2001 Dec; 79(3):511-79.

40. Storkel HL, Armbrüster J, Hogan TP. Differentiating phonotactic probability and neighborhood density in adult word learning. Journal of Speech, Language, and Hearing Research. 2006; 49(6):1175-92.

41. Kendall DL, Oelke M. Phonomotor Treatment for Individuals with Aphasia: Evidence Based Practice. Medbridge Web site. ttps://www.medbridgeeducation.com/courses/details/phonomotor-treatment-forindividuals-with-aphasia-evidence-based-practice. Accessed 2016 August 18.

42. Brookshire CE, Conway T, Pompon RH, Oelke M, Kendall DL. Effects of intensive phonomotor treatment on reading in eight individuals with aphasia and phonological alexia. American Journal of Speech-Language Pathology. 2014 May; 23(2):S300-11. 
43. Kendall DL, Hunting Pompon R, Brookshire CE, Minkina I, Bislick L. An analysis of aphasic naming errors as an indicator of improved linguistic processing following phonomotor treatment. American Journal of Speech-Language Pathology. 2013 May; 22(2):S240-9.

44. Minkina I, Oelke M, Bislick LP, et al. An investigation of aphasic naming error evolution following phonomotor treatment. Aphasiology. 2016; 30(8): 962-980.

45. Edmonds LA, Nadeau SE, Kiran S. Effects of Verb Network Strengthening Treatment (VNeST) on lexical retrieval of content words in sentences in persons with aphasia. Aphasiology. 2009; 23(3):402-24.

46. Kagan A, Simmons-Mackie N. Beginning with the end: Outcome-driven assessment and intervention with life participation in mind. Topics in Language Disorders. 2007; 27(4):309-17.

47. Hunting Pompon R, Burns M, Kendall DL. Counseling the caregiver. ASHA Leader. 2015;20(7):30-32. 


\section{Appendix.}

\begin{tabular}{|c|c|c|}
\hline \multirow[t]{2}{*}{$\begin{array}{l}\text { Treatment } \\
\text { materials }\end{array}$} & \multicolumn{2}{|c|}{$\begin{array}{ll}\text { - } & \text { Small mirror } \\
\text { - } & \text { Line drawings of mouth postures, icons for voiced/voiceless consonants } \\
\text { - } & \text { Letter tiles } \\
\text { - } & \text { Wipe-off board with markers } \\
\text { - } & \text { Small colored blocks }\end{array}$} \\
\hline & Stage 1: Sounds in Isolation & Stage 2: Sounds in syllables \\
\hline Overview & 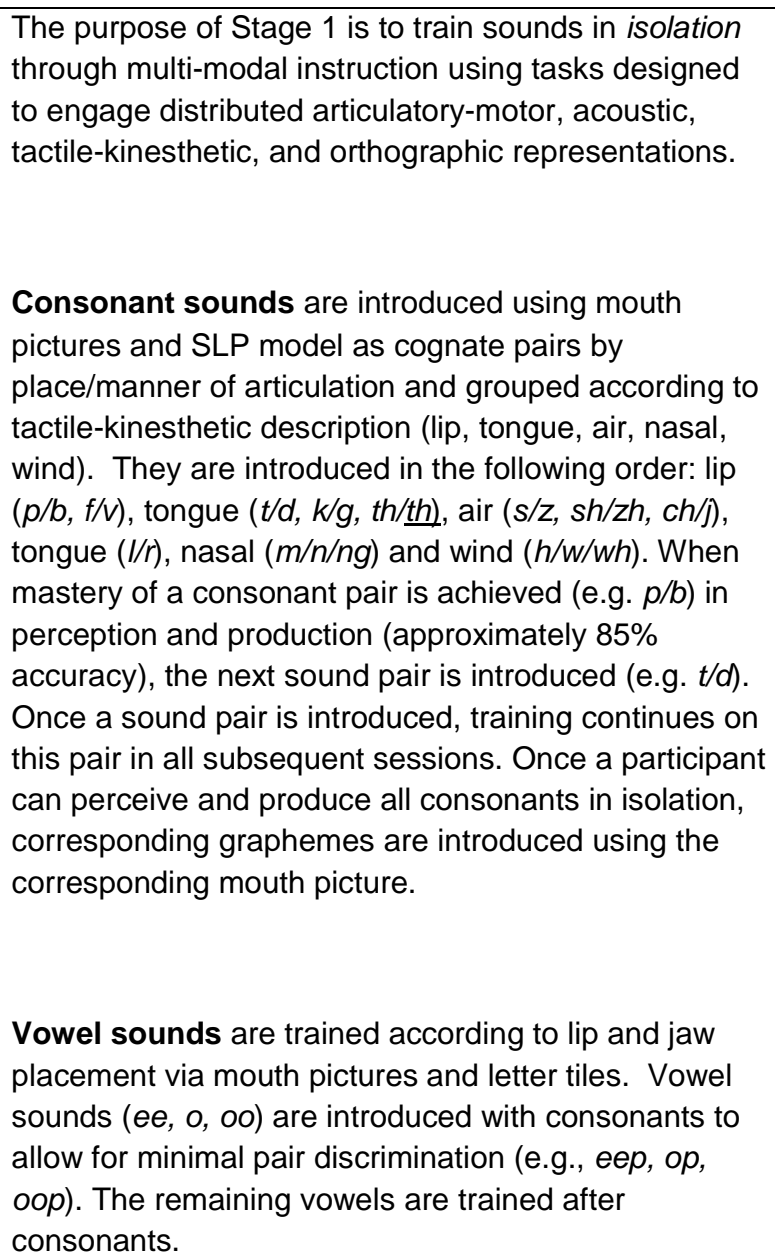 & $\begin{array}{l}\text { The purpose of Stage } 2 \text { is to extend skills } \\
\text { acquired in Stage } 1 \text { to phoneme sequences. } \\
\text { Treatment tasks remain similar to Stage } 1 \\
\text { tasks, with the exception that sounds will be } \\
\text { produced in combinations rather than isolation. } \\
\text { Training progresses from shorter, monosyllabic } \\
\text { sequences to longer, multisyllabic (more } \\
\text { complex) sequences (e.g., VC, CV, CVC, } \\
\text { CCV, VCC, CCVC, CVCC, CCVCC, CVCV). } \\
\text { Both real and nonwords are trained using } \\
\text { phonologic tasks (in other words, only } \\
\text { phonological features, not semantic features, } \\
\text { are trained for real words). Nonword training is } \\
\text { introduced before real word training to allow for } \\
\text { emphasis on phonology; however, as } \\
\text { treatment progresses nonwords and real words } \\
\text { are trained simultaneously. }\end{array}$ \\
\hline
\end{tabular}




\begin{tabular}{|c|c|c|}
\hline $\begin{array}{l}\text { Introduction } \\
\text { of sounds } \\
\text { and sound } \\
\text { sequences }\end{array}$ & $\begin{array}{l}\text { Participant observes SLP producing a single sound } \\
\text { (e.g. Ip/). SLP asks participant what they observed } \\
\text { (heard, saw) and if needed, describes what articulators } \\
\text { are moving and how they move. For the sound /p/, for } \\
\text { example, "the lips come together and blow apart, the } \\
\text { sound is "quiet' so the voice is turned off, the tongue is } \\
\text { not moving." The participant is then shown the line } \\
\text { drawing of the mouth posture corresponding to the } \\
\text { sound. } \\
\text { After looking at the mouth picture and hearing the } \\
\text { SLP's production, the participant is then asked to } \\
\text { repeat the sound while looking in the mirror. The } \\
\text { participant is also asked to place their hand on their } \\
\text { throat in order to feel for vocal fold vibration ("quiet" } \\
\text { versus "noisy"). Following production, the SLP asks } \\
\text { the participant what s/he saw and felt when the sound } \\
\text { was made. Socratic questioning is used to enable the } \\
\text { participant to "discover" the auditory, visual, } \\
\text { articulatory, and tactile/kinesthetic attributes of the } \\
\text { sound (e.g., "What do you feel when you make that } \\
\text { sound? What moved? What did you see when you } \\
\text { made that sound?" etc.). Within therapy progression } \\
\text { for all levels is based on 85\% accurate performance } \\
\text { on task. }\end{array}$ & $\begin{array}{l}\text { The process of "discovering" sounds primarily } \\
\text { occurs in Stage 1; however, knowledge of the } \\
\text { auditory, visual, articulatory and } \\
\text { tactile/kinesthetic attributes of sounds can also } \\
\text { be used later in the program as a cueing } \\
\text { technique to identify individual phonemes } \\
\text { within a phoneme sequence. For example, if a } \\
\text { participant had trouble parsing the initial sound } \\
\text { in peef, the SLP would use Socratic } \\
\text { questioning (e.g., "What do you feel when you } \\
\text { make that first sound? What moved? Did your } \\
\text { lips or tongue move when you made that } \\
\text { sound?" etc.) to help identify the initial sound } \\
\text { Ip/. Put differently, rather than give the } \\
\text { participant a model and tell them what the } \\
\text { initial sound is, the SLP assists the participant } \\
\text { in self-awareness of errors and how to repair } \\
\text { them. }\end{array}$ \\
\hline $\begin{array}{l}\text { Perception } \\
\text { tasks }\end{array}$ & $\begin{array}{l}\text { Perception of sounds in isolation can be trained } \\
\text { through various multi-modal tasks. Examples: } \\
\text { - } \quad \text { Mouth pictures: SLP produces a sound (e.g., } p \text { ) } \\
\text { and asks the participant to choose that sound } \\
\text { from an array of mouth pictures (e.g., } p, b, t, d) \\
\text { Colored blocks: SLP produces a string of } \\
\text { individual sounds (e.g., } p, t, t, b) \text { and asks the } \\
\text { participant to lay out blocks to demonstrate ability } \\
\text { to discriminate sounds (e.g., blocks: red, blue, } \\
\text { blue, green). } \\
\text { Verbal: SLP produces two sounds (e.g., } p, p \text { or } p \text {, } \\
\text { b) and asks the participant "same or different." } \\
\text { Letters: SLP produces a sound and asks } \\
\text { participant to point to the corresponding letter } \\
\text { from an array of letters. }\end{array}$ & $\begin{array}{l}\text { The SLP produces a real or nonword sound } \\
\text { combination and asks the participant to depict } \\
\text { the target through various tasks: } \\
\text { - Mouth pictures: If the participant heard } \\
\text { the CVC peef, they would select the } \\
\text { pictures corresponding to } p \text {, ee, and } f \text {. } \\
\text { Colored blocks: If the participant heard } \\
\text { the CVCV peefee, they would select } \\
\text { three differently colored blocks arranged } \\
\text { in the following order: white, black, red, } \\
\text { black. } \\
\text { Verbal: If the participant heard the } \\
\text { CCVCs grook and glook, the SLP would } \\
\text { ask "same or different." } \\
\text { Letters: If the participant heard chootee, } \\
\text { s/he would select the corresponding letter } \\
\text { tiles. }\end{array}$ \\
\hline
\end{tabular}




\begin{tabular}{|c|c|c|}
\hline $\begin{array}{l}\text { Production } \\
\text { tasks }\end{array}$ & $\begin{array}{l}\text { Production of sounds in isolation can be trained } \\
\text { through various tasks. Here are some examples: } \\
\text { - Mouth pictures: The SLP shows participant a } \\
\text { mouth picture and asks the participant to produce } \\
\text { that sound (e.g., } d \text { ). } \\
\text { - Motor description: The SLP describes a sound } \\
\text { (e.g., "make the sound where your voice is noisy } \\
\text { and your tongue quickly taps the roof of your } \\
\text { mouth") and asks the participant to say the sound. } \\
\text { - Verbal: The SLP asks the participant to repeat a } \\
\text { sound } p \text { or a string of individual sounds } p, p, s, d \text {. } \\
\text { - Letters: The SLP shows the participant a letter to } \\
\text { elicit production of the sound. }\end{array}$ & $\begin{array}{l}\text { The SLP elicits a real or nonword sound } \\
\text { combination by asking the participant to } \\
\text { produce the target through various tasks: } \\
\text { - Mouth pictures: The SLP lays out a } \\
\text { series of mouth pictures and asks the } \\
\text { participant to "touch and say" each sound } \\
(f-e e-p) \text { and then blend the sounds to } \\
\text { produce the target (feep). } \\
\text { Verbal: The SLP asks the participant to } \\
\text { repeat a nonword grook and parse the } \\
\text { word apart ( } g-r-o o-k) \text {. } \\
\text { Letters: The SLP lays out letter tiles (or } \\
\text { writes letters on dry erase board). The } \\
\text { participant parses out the sounds by } \\
\text { underlining and verbalizing each } \\
\text { grapheme and then blends the sounds to } \\
\text { produce the target. }\end{array}$ \\
\hline
\end{tabular}




\section{Figure 1.}

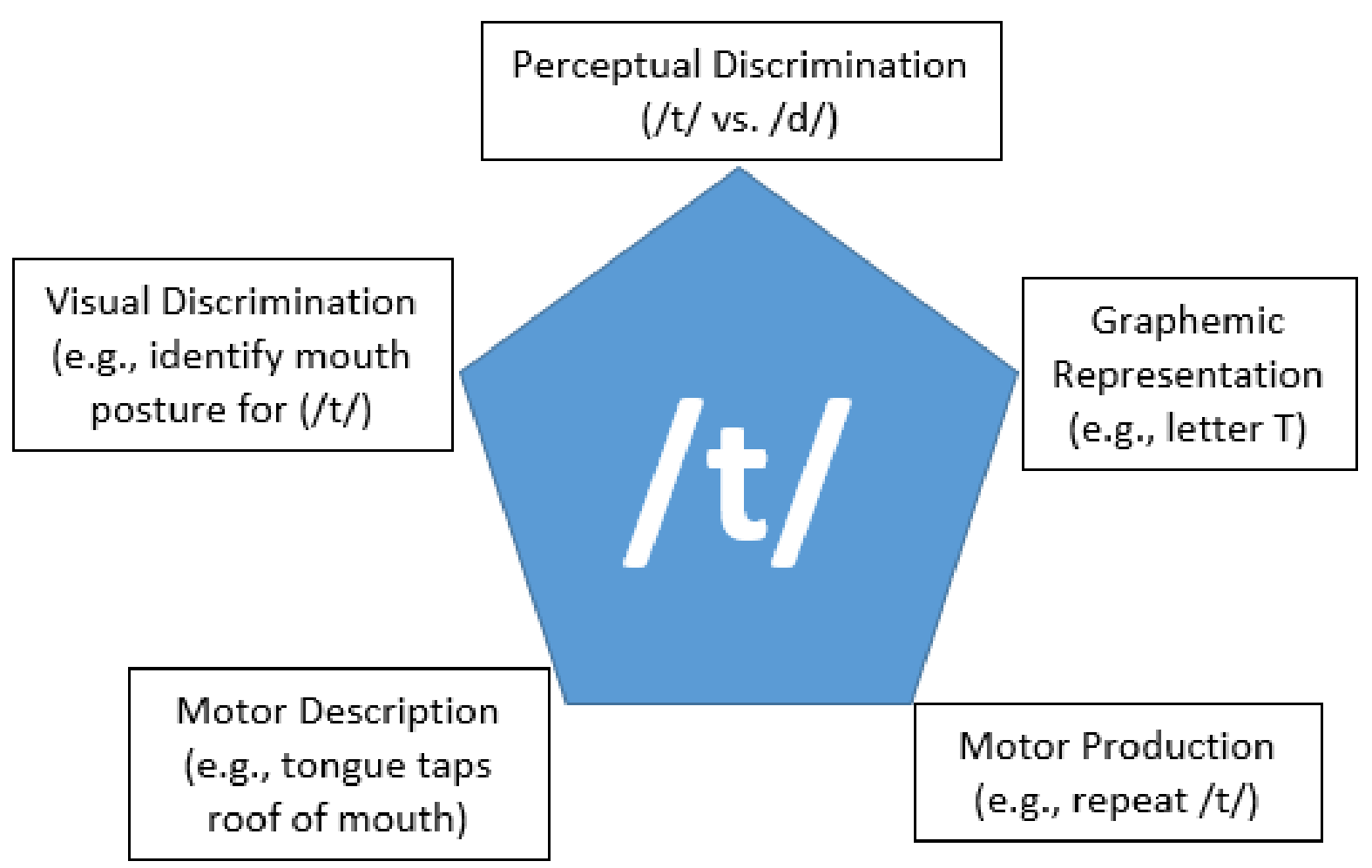


Figure 2:

\begin{tabular}{|c|c|c|c|c|c|c|c|c|c|}
\hline \multirow{2}{*}{\multicolumn{2}{|c|}{\begin{tabular}{|l|} 
Trained sounds in isolation \\
\end{tabular}}} & \multicolumn{4}{|c|}{ Real Words } & \multicolumn{4}{|c|}{ Nonwords } \\
\hline & & \multicolumn{2}{|c|}{ Trained } & \multicolumn{2}{|c|}{ Untrained } & \multicolumn{2}{|c|}{ Trained (graphemes) (IPA) } & \multicolumn{2}{|c|}{ Untrained (graphemes) (IPA) } \\
\hline \begin{tabular}{|l|} 
IPA symbol \\
\end{tabular} & Graphemes & 1 syllabe & 2 syllable & 1 syllable & 2 syllable & 1 syllable & 2 syllable & 1 syllable & 2 syllable \\
\hline$p$ & $\mathrm{p}$ & ape & feeder & toy & tire & doi (dગı) & chootee (tJuti) & ain (eın) & wurkee (wзki) \\
\hline$b$ & $b$ & ache & jockey & age & usher & af (æf) & zhuree (3зi) & poom (pum) & koetoe (kovtov) \\
\hline$f$ & $f$ & itch & ivy & eel & wire & toos (tus) & foekoe (fovkov) & gee (gi) & wayzer (weıza) \\
\hline v & v & edge & gravy & whip & iron & sheev (Jiv) & leber (lebə) & haje (heıdz) & rooit (ruit) \\
\hline $\mathrm{t}$ & $\mathrm{t}$ & bow & lasso & beef & baby & ek ( $(\varepsilon k)$ & doem (dou^m) & loy (וכ) & sayvay (seıveı) \\
\hline d & $d$ & day & tower & birth & valet & dach (dæt)) & mefoe (mefou) & heeg (hig) & fooer (fua) \\
\hline k & $\mathrm{k}$ & hay & shadow & ditch & lady & peenz (pinz) & shever ( (JEvə) & jong (dzan) & laybee (leıbi) \\
\hline$g$ & g & thigh & shoulder & wheel & chauffeur & роа (рошә) & feether (fiðə) & poy (рэ) & grayzee (greızi) \\
\hline$\theta$ & th & cave & treasure & jeans & laughter & meeth ( $\mathrm{mi} \theta$ ) & toiler (tગla) & $a w b(a b)$ & ekee (عki) \\
\hline ð & th & maze & ladder & pie & turkey & ri (rı) & izel (aızl) & jeef (dzif) & badow (bædov) \\
\hline $\mathrm{s}$ & s & boot & teacher & fir & fisher & ish (IJ) & shaybee (Jeıbi) & tay (teı) & nider (naida) \\
\hline$z$ & $z$ & fig & jail & knee & razor & whup (w^p) & veeder (vidə) & mirth $(m 3-\theta)$ & eepoe (ipov) \\
\hline $\int$ & sh & bird & jury & egg & clover & breek (brik) & zower (zavə) & vank (vænk) & vaylow (veılov) \\
\hline 3 & $\mathrm{zh}$ & mop & ranger & rash & fire & voo (vu) & tawthee (ta $\theta i)$ & bap (bæp) & sheefur (Jifa) \\
\hline ts & ch & half & leather & witch & genie & eep (ip) & jiver (dzıvə) & ka (kæ) & hoower (huwa) \\
\hline d3 & j & song & diver & knot & halo & reesh (rif) & wooter (wuta) & ool (ul) & eeshur (ifa) \\
\hline I & I & knob & lawyer & break & meadow & nie (naı) & dungee (d $\wedge$ ji) & wog (wag) & rayger (reigə) \\
\hline$r$ & $r$ & gray & level & bride & shower & iej (aıdz) & turmee (tз-mi) & glane (gleın) & zopper (zapə) \\
\hline $\mathrm{h}$ & $\mathrm{h}$ & plane & owl & bruise & voter & zine (zaın) & lekzher (lعkzみ) & ieg (aıg) & joah (dzovə) \\
\hline w & w & & father & poem & tiger & broiz (brدı) & lekee (lعki) & dite (dait) & tawkee (taki) \\
\hline wh & wh & & heater & & speaker & thag (Өæg) & juroe (d330) & grabe (greıb) & zire (zaıər) \\
\hline $\mathrm{m}$ & $\mathrm{m}$ & & polo & & & oit (ગt) & shashoe ( Jæsov) & jie (dzaı) & thiver ( Өાvみ) \\
\hline $\mathrm{n}$ & $\mathrm{n}$ & & movie & & & $\operatorname{kur}(\mathrm{k} 3)$ & hoyter (hoit) & wawj (wad3) & wiver ( waivə) \\
\hline$\eta$ & $\mathrm{ng}$ & & & & & froos (frus) & neenee (nini) & fie (faı) & uzher $(\wedge 3 \partial)$ \\
\hline $\mathrm{i}$ & ee & & & & & grake (greık) & rayzel (reızl) & oozh (uz) & chafter ( tfæftə) \\
\hline I & $\mathrm{i}$ & & & & & choy (t)د) & highger (haigə) & whike (waık) & osay (oseı) \\
\hline$\varepsilon$ & $\mathrm{e}$ & & & & & $\operatorname{oos}$ (us) & woewuh (wouwə) & gride (graıd) & doojee (dudzi) \\
\hline eI & ae & & & & & wap (wæp) & unger (^ngว) & loich ( lıtt]) & fayshur (felfa) \\
\hline$æ$ & a & & & & & faps (fæps) & miver (maıva) & moy (mગ) & shiloe (filo) \\
\hline$\wedge, \partial$ & u & & & & & woy (wכ) & jawvee (dzavi) & jurl (dz3l) & voker (vovkみ) \\
\hline $\mathrm{a}, \mathrm{\jmath}$ & o, aw & & & & & awch (at)) & prezhur (prعzว) & thed $(\theta \varepsilon d)$ & haybee (heıbi) \\
\hline o, ov & oe & & & & & plown (plaun) & foover (fuvə) & eem (im) & rieger (raıgみ) \\
\hline U & ০o & & & & & zae (zeı) & pire (paı)) & riz (rız) & layfee (leıfi) \\
\hline $\mathrm{u}$ & oo & & & & & hob (hab) & dryper (draıpə) & & meevee (mivi) \\
\hline aI & ie & & & & & veed (vid) & gower (gavə) & & tycher (tait/a) \\
\hline ju & ue & & & & & & teever (tivみ) & & kloper (kloupə) \\
\hline गI & oi, oy & & & & & & ibee (aıbi) & & nyer (naı) \\
\hline$a v$ & ow, ou & & & & & & & & langee ( leıni) \\
\hline $3^{n}, \partial^{n}$ & er, ir, ur & & & & & & & & gainjer (geındzว) \\
\hline or & or & & & & & & & & skonner (skana) \\
\hline ar & ar & & & & & & & & \\
\hline
\end{tabular}




\section{FIGURE LEGENDS}

\section{Appendix}

Title:

Phonomotor treatment protocol

Footnote:

${ }^{\text {a }}$ Reprinted from Kendall and colleagues ${ }^{6}$ with permission from the American Speech Language Hearing Association.

\section{Figure 1}

Title:

Illustration of training the phoneme $/ t /$ in a multi-modal manner

\section{Figure 2}

Title:

Trained and untrained stimuli used in phonomotor treatment

Footnote:

${ }^{\text {a }}$ Reprinted from Kendall and colleagues ${ }^{6}$ with permission from the American Speech Language Hearing Association. 


\section{CONTINUING EDUCATION QUESTIONS}

1) According to the interactive 2-step model of lexical retrieval, when is phonology activated during a language production task?

a) Phonology is activated first, and then activation spreads to semantics.

b) Phonology is activated after activation has spread from semantics.

c) Phonology is activated simultaneously with semantics.

d) Phonology is not activated during language production.

Phonology is not an element of the interactive 2-step model of lexical retrieval.

2) Which of the following is NOT a common phonologically-based treatment cueing method discussed in this article?
a) Mixed cueing
b) Contextual Priming
c) Multiple exemplar cueing
d) Orthographic cueing
e) Guided self-cueing

3) Generalization is often limited in traditional, phonologically-based cueing treatment approaches. Why?

a) Phonological cues only work as part of a hierarchy that includes semantic and syntactic cues.

b) Traditional phonological cueing is word specific and helps establish unique semantic-phonological connections for individual lexical items.

c) Phonological cueing activates too many lexical items and injury to left perisylvian cortex reduces inhibition.

d) Phonological cues are too brief to stimulate correct responses. 
e) Phonological cueing only benefits people with severe phonological impairment.

4) Which of the following are some of the core principles of phonomotor treatment?

\section{a) Phonomotor initially trains phonemes in isolation, uses non-word and real word stimuli, and is multimodal in nature.}

b) Phonomotor involves Socratic questioning, picture naming tasks, and phoneme sequences with high phonotactic probability.

c) Phonomotor uses a unique reward schedule, focuses on phonological awareness, and is intensively delivered.

d) Phonomotor uses stimuli with high neighborhood density and low phonotactic probability, focuses only on low frequency verbs, and is multimodal.

e) Phonomotor employs phonological awareness tasks, trains phonemes in isolation, and focuses on orthographic cues.

5) This article suggests that phonomotor treatment should be considered as part of a multifaceted plan of care. What other approaches do the authors recommend?
a) Verb Network Strengthening Treatment (VNest)
b) Patient and caregiver training for home practice
c) Addressing psychosocial concerns associated with aphasia

\section{d) All of the above \\ e) None of the above}




\section{LEARNING OBJECTIVES}

1) The reader will be able to summarize the role of phonology in language processing and the effects of phonological impairment in aphasia.

2) The reader will be able to discuss traditional phonologically-based treatment approaches for spoken word production impairment in aphasia and explain differences between those treatment methods and phonomotor treatment methods.

3) The reader will be able to explain the difference between acquisition, maintenance, and generalization treatment effects.

\section{BIOGRAPHIES}

Elizabeth Brookshire Madden, PhD, CCC-SLP, is an assistant professor in the School of Communication Science and Disorders and an affiliate of the Institute for Successful Longevity at Florida State University. She completed her PhD in Speech \& Hearing Sciences at the University of Washington and her clinical training in speech-language pathology at Vanderbilt University School of Medicine. She studies aphasia rehabilitation and is particularly interested in the relationship between spoken and written language performance in aphasia.

Reva Robinson, MS, CCC-SLP, received her BA in Linguistics and BS in Speech and Hearing Sciences from the University of Washington, and her MS in Speech-Language Pathology from the University of British Columbia. She serves as a research associate on Dr. Malcom McNeil's study exploring conflict resolution and short-term memory in aphasic comprehension. In addition, she is currently completing her $\mathrm{PhD}$ under the mentorship of Dr. Diane Kendall in the Department of Speech \& Hearing Sciences at the University of Washington. 
Diane L. Kendall, PhD, CCC-SLP, is the Chair of the Department of Speech and Hearing Sciences, a Professor, and Director of the Aphasia Research Laboratory at the University of Washington. She is also a research scientist at the VA Puget Sound Healthcare System. Her research focuses on rehabilitation of aphasia, and in particular, understanding the theoretical relationship between phonology and word retrieval deficits. 